\title{
Conjunctive use of surface water and groundwater via the bank infiltration method
}

\begin{abstract}
The bank infiltration (BI) technique may be a viable option if the local climate, hydrological, and geological conditions are conducive. This study was specifically conducted to explore the possibility of using BI to source the polluted surface water in conjunction with groundwater. Three major factors were considered for evaluation: (1) investigation on the contribution of surface water through BI, (2) input of local groundwater, and (3) water quality characteristics of water supply. Initially, the geophysical method was employed to define the subsurface geology and hydrogeology, and isotope techniques were performed to identify the source of groundwater recharge and interaction between surface water and groundwater. The physicochemical and microbiological parameters of the local surface water bodies and groundwater were analyzed before and during water abstraction. Extracted water revealed a 5 $\%$ concentration reduction compared with those of Langat river water. However, water samples from test wells during pumping show high concentrations of $\mathrm{Fe} 2+$ and $\mathrm{Mn} 2+$. In addition, amounts of Escherichia coli, total coliform, and Giardia were significantly reduced (99.9\%). Pumping test results indicate that the two wells (DW1 and DW2) were able to sustain yields.
\end{abstract}

Keyword: Bank infiltration; Hydrochemistry; Alluvial aquifer; Groundwater/surface water relations 